\title{
Laminar Fate and Phenotype Specification of Cerebellar GABAergic Interneurons
}

\author{
Ketty Leto, ${ }^{1 \star}$ Alice Bartolini, ${ }^{1 \star}$ Yukio Yanagawa, ${ }^{2}$ Kunihiko Obata, ${ }^{3}$ Lorenzo Magrassi, ${ }^{4}$ Karl Schilling, ${ }^{5}$ and \\ Ferdinando Rossi ${ }^{1}$ \\ ${ }^{1}$ Department of Neuroscience and Rita Levi-Montalcini Center for Brain Repair, Neuroscience Institute of Turin, University of Turin, I-10125 Turin, Italy, \\ ${ }^{2}$ Department of Genetic and Behavioral Neuroscience, Gunma University Graduate School of Medicine, Maebashi 371-8511, Japan, ${ }^{3}$ RIKEN Brain Science \\ Institute, Wako, Saitama 351-0198, Japan, ${ }^{4}$ Neurosurgery, Department of Surgical Sciences, Fondazione Istituto Di Ricovero e Cura a Carattere Scientifico \\ Policlinico S. Matteo, University of Pavia, 27100 Pavia, Italy, and ${ }^{5}$ Anatomisches Institut, Anatomie und Zellbiologie, Rheinische Friedrich-Wilhelms- \\ Universität, 53115 Bonn, Germany
}

In most CNS regions, the variety of inhibitory interneurons originates from separate pools of progenitors residing in discrete germinal domains, where they become committed to specific phenotypes and positions during their last mitosis. We show here that GABAergic interneurons of the rodent cerebellum are generated through a different mechanism. Progenitors for these interneurons delaminate from the ventricular neuroepithelium of the embryonic cerebellar primordium and continue to proliferate in the prospective white matter during late embryonic and postnatal development. Young postmitotic interneurons do not migrate immediately to their final destination, but remain in the prospective white matter for several days. The different interneuron categories are produced according to a continuous inside-out positional sequence, and cell identity and laminar placement in the cerebellar cortex are temporally related to birth date. However, terminal commitment does not occur while precursors are still proliferating, and postmitotic cells heterochronically transplanted to developing cerebella consistently adopt host-specific phenotypes and positions. However, solid grafts of prospective white matter implanted into the adult cerebellum, when interneuron genesis has ceased, produce interneuron types characteristic of the donor age. Therefore, specification of cerebellar GABAergic interneurons occurs through a hitherto unknown process, in which postmitotic neurons maintain broad developmental potentialities and their phenotypic choices are dictated by instructive cues provided by the microenvironment of the prospective white matter. Whereas in most CNS regions the repertoire of inhibitory interneurons is produced by recruiting precursors from different origins, in the cerebellum it is achieved by creating phenotypic diversity from a single source.

\section{Introduction}

Inhibitory interneurons comprise wide varieties of phenotypes, characterized by distinctive morphological, neurochemical, and functional properties, with specific connectivities and positions. Integration of inhibitory components into maturing circuitries requires that different categories of interneurons are produced according to precise spatiotemporal patterns. Interneuron progenitors are usually committed to specific identities and locations during their last mitosis, when they still reside in germinal neuroepithelia (McConnell and Kaznowski, 1991; Valcanis and Tan, 2003; Lledo et al., 2008). Furthermore, in different CNS regions,

Received Feb. 25, 2009; revised April 29, 2009; accepted May 2, 2009.

This work was supported by grants from Ministero dell'Università e della Ricerca Scientifica e TecnologicaProgretti di Rilevante Interesse Nazionale (2007 programme number 2007F7AJYJ), Compagnia di San Paolo (Neurotransplant Project 2004.2019), Regione Piemonte (Project A14/05), and the University of Turin. K.L. is supported by a fellowship funded by Fondazione per la Ricerca Biomedica Onlus. We are indebted to Luisella Milano and Dr. Francesco Bertolo for valuable technical assistance. We thank Giacomo Consalez for thoughtful comments on this manuscript.

${ }^{*}$ K.L. and A.B. contributed equally to this work.

Correspondence should be addressed to Ferdinando Rossi, Rita Levi-Montalcini Center for Brain Repair, Department of Neuroscience, Section of Physiology, University of Turin, Corso Raffaello 30, I-10125 Turin, Italy. E-mail: ferdinando.rossi@unito.it.

D01:10.1523/JNEUROSC1.0957-09.2009

Copyright $\odot 2009$ Society for Neuroscience $\quad$ 0270-6474/09/297079-13\$15.00/0 including spinal cord (Lee and Jessell, 1999), cerebral cortex (Wonders and Anderson, 2006; Fogarty et al., 2007), or olfactory system (De Marchis et al., 2007; Lledo et al., 2008), the arrays of local interneurons are generated from separate pools of faterestricted progenitors following strict ontogenetic schedules. Although these studies suggest a common strategy to regulate the genesis of interneurons along the neuraxis, recent observations concerning cerebellar development seem not readily reconcilable with this concept.

All cerebellar GABAergic neurons originate from Ptf1-aexpressing cells located in the ventricular neuroepithelium (VN) (Hoshino et al., 2005). Projection neurons (Purkinje cells and nucleo-olivary neurons) are specified within this primary germinal site at the onset of cerebellar neurogenesis (Miale and Sidman, 1961; Altman and Bayer, 1997). In contrast, inhibitory interneurons derive from progenitors that delaminate from the VN during embryonic life and continue to divide in the prospective white matter (PWM) up to postnatal development (Zhang and Goldman, 1996). These cells, distinguished by transient expression of Pax-2 (Maricich and Herrup, 1999; Weisheit et al., 2006), generate the entire repertoire of cerebellar inhibitory interneurons, characterized by distinctive phenotypes and positions in the deep nuclei and cortical layers, according to a precise ontogenetic sequence (Altman and Bayer, 1997; Yamanaka et al., 2004; Schill- 
ing et al., 2008). The progenitors that proliferate in the PWM might have been committed to specific interneuron identities before their emigration from the $\mathrm{VN}$, or could become progressively fate-restricted as development advances. Heterotopic/heterochronic transplantation experiments show that these cells retain broad developmental potentialities throughout cerebellar ontogenesis (Leto et al., 2006). Nevertheless, it is still unknown how cerebellar inhibitory interneurons adopt specific identities and laminar fates and whether their phenotypic choices are related to the mitotic activity of the progenitors in the PWM.

Here, we tested the hypothesis that interneuron phenotypes and positions are specified by instructive mechanisms that operate on multipotent cells in the PWM. By fate mapping analysis and heterochronic transplantation, we found that the phenotype and laminar placement of cerebellar interneurons are temporally related to their birth date. However, postmitotic interneurons exposed to a heterochronic milieu remain fully able to switch their fate, showing that they are still uncommitted. Analysis of grafted cells or maturing interneurons in situ indicates that fate choices are taken in the PWM, where neonate interneurons sojourn before moving to their final destination. Therefore, contrary to other CNS regions, the variety of cerebellar GABAergic interneurons derives from a single population of multipotent cells that become specified after their last division in the PWM, away from their primary germinal site.

\section{Materials and Methods}

\section{Animals and surgical procedures}

All experiments were performed on wild-type Wistar rats and C57BL/6 mice (Harlan). In addition, several lines of transgenic animals were used: $\beta$-actin-green fluorescent protein (GFP) rats and mice (Okabe et al., 1997), Pax-2-GFP mice [a generous gift from Dr. M. Busslinger, Vienna Biocenter, Vienna, Austria (Pfeffer et al., 2002)], and glutamate decarboxylase (Gad) 67-GFP ( $\Delta$ neo) (Gad67-GFP) mice (Tamamaki et al., 2003; Yamanaka et al., 2004). For some transplantation experiments we used double transgenic mice obtained by cross-breeding Pax-2-GFP and $\beta$-actin-red fluorescent protein (RFP) mice [a generous gift from Dr A. Vercelli, University of Turin, Turin, Italy (Long et al., 2005)]. In Pax-2GFP mice, GFP is selectively expressed in all types of immature and mature interneurons (Weisheit et al., 2006) (supplemental Fig. 1a-d, available at www.jneurosci.org as supplemental material). GFP expression intensity correlates with anti-Pax-2 immunolabeling (Weisheit et al., 2006) but persists after the downregulation of Pax-2 protein that occurs in mature basket and stellate cells (Maricich and Herrup, 1999). In Gad67-GFP mice, GFP is consistently expressed in all GABAergic neurons of the cerebellum, including Purkinje cells and inhibitory interneurons (Tamamaki et al., 2003; Yamanaka et al., 2004; Simat et al., 2007a).

All surgical procedures were performed under deep general anesthesia obtained by intraperitoneal administration of ketamine $(100 \mathrm{mg} / \mathrm{kg})$ (Ketavet; Bayer) supplemented by xylazine $(5 \mathrm{mg} / \mathrm{kg}$ ) (Rompun; Bayer) or diazepam $(2.5 \mathrm{mg} / \mathrm{kg})$ (Roche). The experimental plan was designed according to the European Communities Council Directive of 1986 (86/ 609/EEC), National Institutes of Health guidelines, and the Italian law for care and use of experimental animals (DL116/92), and was approved by the Italian Ministry of Health.

\section{Transplantation experiments}

Donor cells for transplantation experiments were isolated from rat or mouse donors of different embryonic and postnatal ages and grafted to syngenic hosts, according to previously established procedures for transplantation in utero or in vivo (Jankovski et al., 1996; Carletti et al., 2002). Solid grafts of PWM were prepared by carefully dissecting small tissue blocks from the periventricular region of the donor cerebellum (Leto et al., 2006). One or two of these blocks were pressure injected in each recipient cerebellum via a glass capillary, according to previously established procedures (Rossi et al., 1992). Single-cell suspensions were obtained by mechanical dissociation of embryonic cerebellar primordia or of tissue blocks from postnatal cerebella. One microliter of the obtained suspension (final concentration $5^{\star} 10^{4}$ cells/ $\mu$ l) was injected through a glass capillary to postnatal cerebella or in the fourth ventricle of embryonic hosts. Reaggregates of dissociated cells were obtained by gently shaking the cell suspension in a $0.5 \mathrm{ml}$ Eppendorf vial for $\sim 30 \mathrm{~min}$ at room temperature. The obtained cell aggregates were carefully collected by a glass capillary and immediately transplanted. Recipient animals were killed at different survival times post-transplantation, as detailed in Results.

\section{Fluorescence-activated cell sorting of donor cells}

Cerebella of postnatal day 7 (P7) Gad67-GFP mice were dissected and dissociated as above. The cell suspension was filtered through cell strainers $(70 \mu \mathrm{m}, \mathrm{BD}$ Biosciences) to remove cellular aggregates and resuspended in sorting buffer (PBS $1 \times$, EDTA 5 mM, HEPES $25 \mathrm{~mm}, \mathrm{pH} 7.0$, HBS $1 \%$ ) at a concentration of $1^{\star} 10^{6}$ to $10^{\star} 10^{7}$ cells $/ \mathrm{ml}$. The cell suspension was fluorescence-activated cell sorted using a Dako Cytomation MoFlo cell sorter. The purity of sorted cells was checked microscopically. The sorted cells were transplanted to $\mathrm{P} 1$ recipients (as above), which were examined 1 month later (58 GFP-positive interneurons/4 cases).

\section{Histological procedures}

Under deep general anesthesia, experimental animals were transcardially perfused with $4 \%$ paraformaldehyde in $0.12 \mathrm{~m}$ phosphate buffer, $\mathrm{pH}$ $7.2-7.4$ ( $500 \mathrm{ml}$ for rats, $250 \mathrm{ml}$ for mice). The brains were immediately dissected, stored overnight in the same fixative at $4^{\circ} \mathrm{C}$, and finally transferred in $30 \%$ sucrose in $0.12 \mathrm{~m}$ phosphate buffer. The cerebella were cut with a cryostat in $30-\mu \mathrm{m}$-thick parasagittal slices collected in PBS. Slices obtained from different experimental sets were processed for immunofluorescent labeling with different primary antibodies (all dissolved in PBS with $1.5 \%$ normal serum and $0.25 \%$ Triton X-100): antiparvalbumin (1:1500, monoclonal; Swant), Pax-2 (1:200, polyclonal; Zymed), anti-phospho-histone H3 (1:100, polyclonal, Upstate Biotechnology), anti-neurogranin (1:250; polyclonal; Millipore Bioscience Research Reagents), anti-Ng2 (1:200; polyclonal; Millipore Bioscience Research Reagents), anti-S100 (1:1000, monoclonal, Sigma), anti-Olig2 (1: 500; polyclonal; Millipore Bioscience Research Reagents), anti-GFP (1: 700, polyclonal or monoclonal; Invitrogen), anti-RFP (1:500, Abcam), anti-BrdU (1:500, monoclonal, Sigma) (see Leto et al., 2006 for technical details).

Microscopy and image processing. Histological specimens were examined using a Zeiss Axiophot light microscope equipped with a Nikon DS-5M digital camera, or a Fluoview 300 microscope confocal microscope (Olympus). Adobe Photoshop 6.0 (Adobe Systems) was used to adjust image contrast and assemble the final plates. Some quantitative and morphometric evaluations were made using ImageJ (Research Service Branch, National Institutes of Health, Bethesda, MD; http://rsb.info.nih.gov/ij/).

Birth-dating analysis of interneuron progenitors in situ. BrdU $(5 \mathrm{mg} / \mathrm{ml}$ in $0.007 \mathrm{~N} \mathrm{NaOH}$ in saline) was intraperitoneally injected ( $50 \mu \mathrm{g} / \mathrm{g}$ body weight) to pregnant dams or postnatal pups with different administration schedules and survival times, depending on the specific experiment. To determine the birth date of cerebellar interneurons, BrdU was pulsed twice within 8 h to embryonic day 15 (E15) (259 cells/2 cases), P1(444 cells/4 cases), P7 ( 524 cells/3 cases) wild-type rats, and to E12, P0, P5, and P10 Pax-2-GFP and Gad67-GFP transgenic mice (at least 80 cells/case, 3 cases/age group). The treated animals were killed at P30, and separate series of cerebellar sections were double stained for BrdU and cell typespecific markers to identify their phenotype (see Fig. $2 a-c$ ). Laminar position was recorded as the distance from the Purkinje cell layer (positive for the molecular layer, and negative for the granule cell layer). Raw measurements were normalized relative to layer thickness, and are represented as scatter diagrams that combine measures obtained from different animals of the same set (see Fig. $2 e$, supplemental Fig. 1, available at www.jneurosci.org as supplemental material).

To determine the site of proliferation of cerebellar interneuron progenitors, single $\mathrm{BrdU}$ pulses were injected to $\mathrm{P} 1, \mathrm{P} 6$, or $\mathrm{P} 9$ wild-type mice ( $n=14)$, Pax-2-GFP mice $(n=14)$, and Gad67-GFP mice $(n=6)$, which were killed 2 h, 24 h, or $4 \mathrm{~d}$ later. Vermal sections from these cerebella 

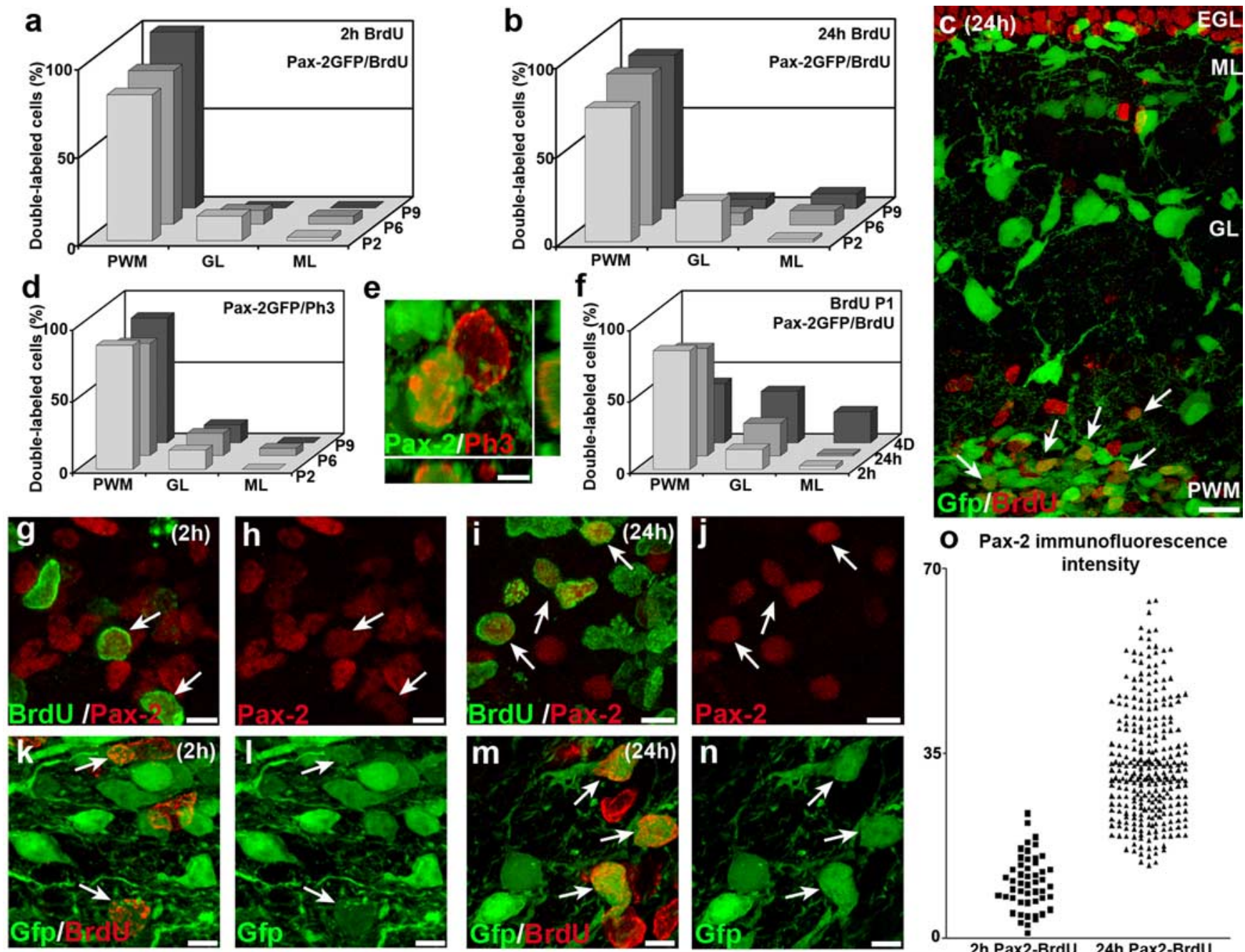

O Pax-2 immunofluorescence
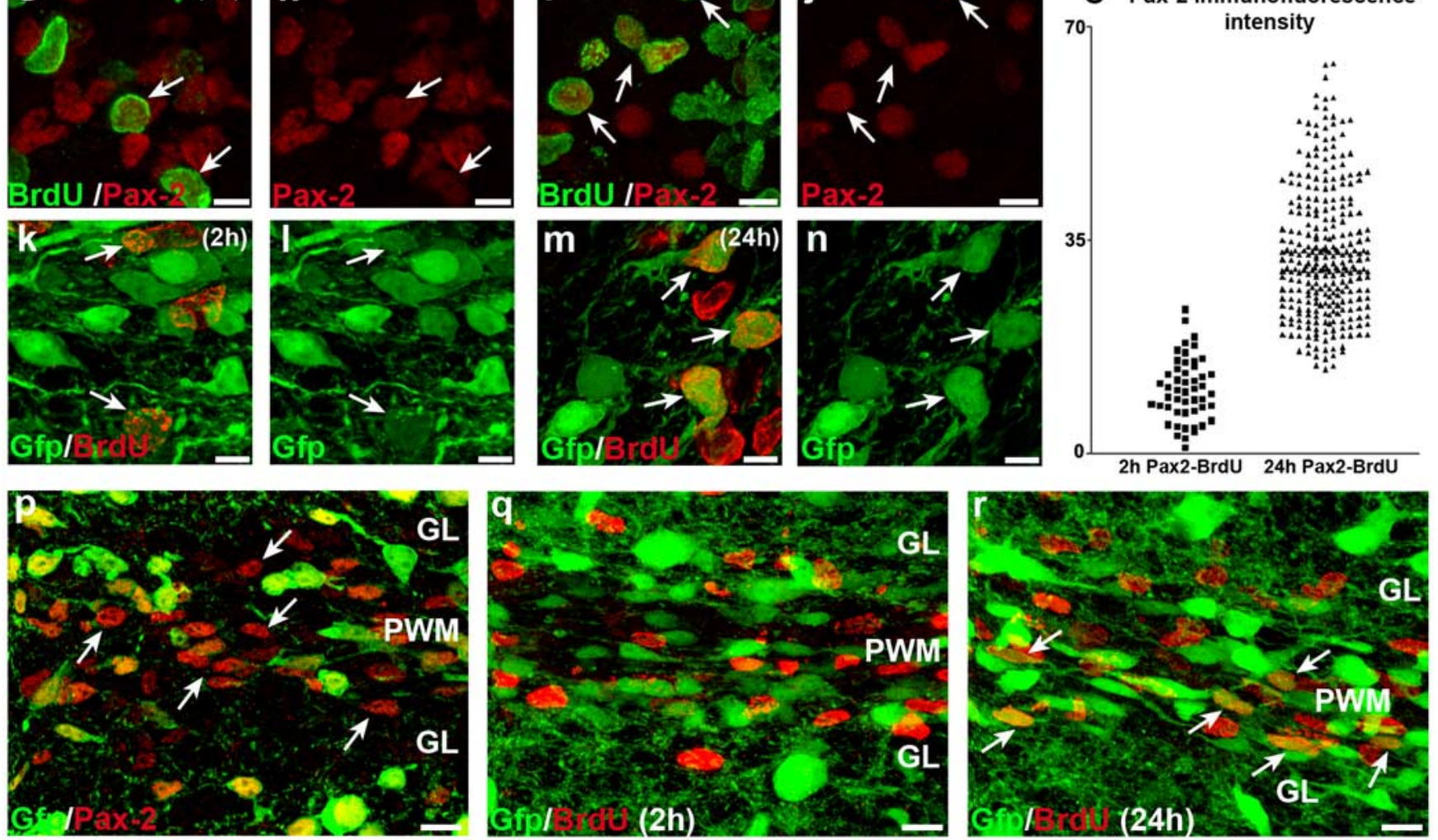

Figure 1. Proliferation and initial differentiation of interneuron precursors in the PWM. $\boldsymbol{a}-\boldsymbol{c}$, Distribution of dividing interneuron precursors in Pax-2-GFP transgenic mice at three different postnatal ages (P2, P6, P9). $\boldsymbol{a}, \boldsymbol{b}$, Graphs illustrate the frequency of GFP/BrdU double-labeled cells in PWM and cortical layers, $2 \mathrm{~h}(\boldsymbol{a})$ or $24 \mathrm{~h}(\boldsymbol{b})$ after BrdU administration ( $n=2-4$ cases/time point). $\boldsymbol{c}-\boldsymbol{e}$, The majority of dividing cells are located in the PWM (arrows in $\boldsymbol{c}$ ). This distribution is confirmed by immunostaining for phospho-histone Ph3 (d, e). $\boldsymbol{f}$, Laminar position of GFP/BrdU-doublelabeled cells at increasing times after BrdU injection: $4 \mathrm{~d}$ after nucleotide analog administration, many cells are still in the PWM. $\boldsymbol{g}-\boldsymbol{n}$ shows Pax- 2 immunolabeling $(\boldsymbol{g}-\boldsymbol{j})$ or Pax-2/GFP expression $(\boldsymbol{k}-\boldsymbol{n})$ in interneuron precursors labeled by $\operatorname{BrdU} 2 \mathrm{~h}(\boldsymbol{g}, \boldsymbol{h}, \boldsymbol{k}, \boldsymbol{I})$ or $24 \mathrm{~h}(\boldsymbol{i}, \boldsymbol{j}, \boldsymbol{m}, \boldsymbol{n})$ before animals were killed. $\boldsymbol{0}, \boldsymbol{p}$, Double-labeled cells (arrows) consistently show a weaker Pax-2 expression at $2 \mathrm{~h}$ than at $24 \mathrm{~h}$, as confirmed by the quantitative estimation of Pax-2 immunofluorescence intensity (o, Student's $t$ test, $p<0.001$ ). $\boldsymbol{p}$ shows the PWM of a P5 Gad67-GFP mouse: double immunostaining for GFP (green) and Pax-2 (red) reveals numerous cells positive for Pax-2 (arrowheads) but negative for GFP. $q$, $r$ display double immunolabeling for GFP ( $g r e e n)$ and BrdU (red) in P5 Gad67-GFP mice. Double-labeled cells are not present $2 \mathrm{~h}$ after injection $(\boldsymbol{q})$, whereas they are evident at $24 \mathrm{~h}$ (arrows in $\boldsymbol{r}$ ). EGL, External granular layer; ML, molecular layer; $\mathrm{GL}$, granular layer. Scale bars: $(\boldsymbol{c}, \boldsymbol{e}, \boldsymbol{p}-\boldsymbol{r}), 20 \mu \mathrm{m} ; \boldsymbol{( g - n )}, 10 \mu \mathrm{m}$.

were double-labeled for BrdU and Pax-2 (wild-type animals) or GFP (transgenic animals). On these sections we estimated the total number and the position of BrdU-positive cells and of double-labeled cells in the PWM or in the cortical layers of lobule IV/V (Fig. 1a,b,f, 2-4 cases/time point). The same procedure was applied to assess the distribution of cells double-labeled for phospho-histone H3 and GFP in P2, P6, and P9 cerebella (Fig. 1d, 2-3 cases/age group).
To check the matching between GFP and Pax-2 expression in the Pax-2-GFP transgenic mice, we immunolabeled cerebellar sections from $\mathrm{P} 2, \mathrm{P} 6$, and $\mathrm{P} 9$ transgenic mice with anti-Pax-2 antibodies (supplemental Fig. $1 a-d$, available at www.jneurosci.org as supplemental material). On such sections, we sampled several hundred cells (500-700/age group, 2-3 cases/age group) positive for either GFP or Pax-2 and checked whether they were also positive for the other. To assess the level of Pax-2 expres- 
sion in proliferating interneuron progenitors, we measured the intensity of anti-Pax-2 immunostaining in wild-type mice or of GFP expression in transgenic animals, which survived 2 or $24 \mathrm{~h}$ after a BrdU pulse. Staining intensity was measured by means of the Neurolucida system on single confocal sections of Pax-2/BrdU double-labeled cells ( 50 cells/7 animals at $2 \mathrm{~h}, 286$ cells/7 animals at $24 \mathrm{~h}$ ).

Analysis of transplanted interneurons. Donor cells in the host tissue were recognized by the intrinsic GFP expression. The phenotypes were identified according to morphological features and expression of several type-specific markers. Cerebellar inhibitory interneurons comprise interneurons of the deep nuclei, Golgi and Lugaro cells in the granular layer, basket and stellate cells in the molecular layer. A host of recent neuroanatomical studies has revealed an unexpected heterogeneity in the repertoire of granular layer interneurons, describing different subtypes, distinguished by morphological (Lainé and Axelrad, 1994, 2002) or neurochemical traits (Geurts et al., 2003; Simat et al., 2007b; Leto et al., 2008). Nonetheless, considering the complexity of the interneuron variety and the low frequency of some of these subtypes, we decided to restrict our classification to major morphological phenotypes and typespecific markers: NeuN and calretinin for deep nuclei interneurons (Leto et al., 2006), calretinin and neurogranin for granular layer interneurons (Lainé and Axelrad, 2002; Simat et al., 2007b), and parvalbumin for molecular layer interneurons (Celio, 1990; Bastianelli, 2003).

The same procedures described above were applied to record the positions of donor interneurons in the different transplantation experiments, including dissociated, reaggregated, and solid grafts, as well as analyses of donor cell proliferation. Because of the variable amounts of donor cells that engrafted in different cases, results obtained from different cases belonging to the same experimental set were usually pooled together. The number of cells considered to determine the position of donor interneurons in grafts of dissociated cells are reported in Figure $2 f$. The position of donor cells from reaggregated grafts to $\mathrm{P} 1$ recipients was determined on a sample of 78 cells $/ 5$ cases (see Fig. $5 b$ ). The position of donor cells from solid grafts to $\mathrm{P} 1$ recipients was determined on a sample of 376 cells/4 cases (see Fig. $5 c$ ). Transplants of dissociated cells to adult recipients included $\mathrm{P} 1$ ( 86 cells/2 cases) and P7 donors ( 332 cells $/ 4$ cases). Solid transplants to adult recipients included P1 (333/3 cases) and P7 donors (311/3 cases).

To analyze the mitotic activity of donor cells after transplantation, recipient animals $(n=8)$ received two injections of BrdU during the first $24 \mathrm{~h}$ post-transplantation. To visualize transplanted cells that completed their last division in the donor cerebellum, single BrdU pulses were administered to donor animals $8 \mathrm{~h}$ ( 61 cells $/ 8$ cases) or $24 \mathrm{~h}$ ( 64 cells $/ 6$ cases) before dissection. Recipient cerebella were processed for BrdU immunoreactivity and type-specific labeling 1 month post-transplantation. Phenotypes and positions were determined as described above. To determine the site in the host cerebellum where transplanted cells proliferate, we made two BrdU injections (within a $3 \mathrm{~h}$ period) to recipient pups at 1,2 , or $4 \mathrm{~d}$ post-transplantation ( $100-250$ cells/age, 3 cases/age). These animals were killed $2 \mathrm{~h}$ after the last injection and the position of BrdUlabeled donor cells was recorded as above. Finally, six transplants of Pax-2-GFP/ $\beta$-actin-RFP donor were examined to investigate the differentiation of donor interneurons (150-250 cells/age, 2 cases/age).

\section{Statistical analysis}

Statistical significance was assessed by a one-way ANOVA with Bonferroni's multiple comparison post-test to analyze whether differences between data sets were significant. An unpaired Student's $t$ test was used in which only two groups were analyzed. In all instances, $p<0.05$ was considered as statistically significant.

\section{Results \\ Progenitors of cerebellar inhibitory interneurons proliferate and initiate GABAergic differentiation in the PWM}

Although the main phases of interneuron genesis and development are well established (Zhang and Goldman, 1996; Altman and Bayer, 1997; Maricich and Herrup, 1999; Yamanaka et al., 2004; Weisheit et al., 2006; Simat et al., 2007a; Schilling et al., 2008), details of progenitor proliferation and initial differentia- tion are still unresolved. To investigate the early phases of interneuron development, we examined Pax-2 expression in wildtype mice or GFP fluorescence in Pax-2-GFP mice. According to previous studies, in the cerebellum anti-Pax-2 immunostaining identifies a population of neuronally restricted GABAergic cells (Maricich and Herrup, 1999), corresponding to the entire repertoire of cerebellar inhibitory interneurons (Maricich and Herrup, 1999; Simat et al., 2007a). In addition, in Pax-2-GFP mice, the Pax-2 protein and GFP are faithfully colocalized (Weisheit et al., 2006). To further confirm these findings, we examined samples of 500-700 cells from P2, P6, or P9 Pax-2-GFP mouse cerebella stained with anti-Pax-2 antibodies and consistently found $>98 \%$ correspondence (supplemental Fig. 1 $a-d$, available at www. jneurosci.org as supplemental material). In all instances, Pax-2expressing cells displayed morphological and neurochemical features of cerebellar interneurons (see below) (Weisheit et al., 2006; Simat et al., 2007a). On the contrary, immunolabeling of the same cerebella with antibodies that recognize glial lineages never colocalized with GFP (supplemental Fig. 1e-g, available at www.jneurosci.org as supplemental material). Therefore, we considered Pax- 2 as a selective and specific marker for maturing cerebellar interneurons.

To define the sites where GABAergic interneuron progenitors proliferate, we injected BrdU to P1, P6 or P9 wild-type mice or Pax-2-GFP transgenic mice, which were killed $2 \mathrm{~h}, 24 \mathrm{~h}$, or $4 \mathrm{~d}$ later. At these ages, dividing cells in the cerebellar parenchyma comprise progenitors for inhibitory interneurons and glial cells (Milosevich and Goldman, 2002, 2004; Grimaldi et al., 2009) (supplemental Fig. $1 h-j$, available at www.jneurosci.org as supplemental material). As a consequence, only a fraction of the BrdU incorporating cells also expressed Pax-2 (5.2\% at $2 \mathrm{~h}, 8.4 \%$ at $24 \mathrm{~h}, 8 \%$ at $4 \mathrm{~d}$ ). At all examined ages, $2 \mathrm{~h}$ after injection cells double-labeled for BrdU and Pax-2 or GFP were located in the PWM and, less frequently, in the adjacent cortex (Fig. 1a). A similar distribution was found $24 \mathrm{~h}$ after BrdU administration (Fig. $1 b, c)$ and also in age-matched animals immunostained for phospho-histone $\mathrm{H} 3$ to visualize cells in late $\mathrm{G}_{2}$ or $\mathrm{M}$ phases (Fig. $1 d, e$ ). Thus, the vast majority of Pax-2-positive interneuron progenitors that proliferate do so in the PWM (Maricich and Herrup, 1999).

It is unclear whether Pax-2 expression occurs in actively dividing progenitors (Maricich and Herrup, 1999) or begins coincident with terminal mitosis (Weisheit et al., 2006). To elucidate this point, we compared levels of Pax-2 expression in BrdUlabeled cells at 2 or $24 \mathrm{~h}$ survival. If Pax- 2 is expressed in actively dividing cells, the level of expression should not be related to the duration of the survival period after BrdU administration. On the contrary, if Pax-2 is upregulated near the last mitosis, one would predict that cells that survive for $2 \mathrm{~h}$ show weaker staining intensity than cells that are fixed $24 \mathrm{~h}$ later. This is indeed what we found. Both immunostaining for Pax-2 in wild-type animals (Fig. $1 g-j$ ) and assessment of Pax-2-GFP in transgenic animals (Fig. $1 k-n)$ showed that levels of Pax-2 expression were consistently lower in cells analyzed $2 \mathrm{~h}$ after BrdU administration, compared with cells that survived for $24 \mathrm{~h}$ (Fig. 1o, Student's $t$ test, $p<$ 0.001 ) (comparable results were obtained from the analysis of Pax-2-GFP mice; data not shown). Therefore, interneuron progenitors start Pax-2 expression at about the time of the S-phase of their last mitosis.

Four days after application of the BrdU pulse, Pax-2expressing cells that had retained the nucleotide analog were found distributed throughout all cortical layers (Fig. 1f). Nevertheless, many of them $(41,7 \%)$ were still in the PWM, indicating 
that Pax-2-positive postmitotic cells do not migrate immediately to their final destinations. During this protracted period of transit through the PWM, young interneurons progress in their maturation. For instance, expression of the GABA-synthesizing enzyme, Gad67, occurs subsequent to that of Pax-2, as verified by the observation that, in Gad67-GFP mice, many Pax-2-positive cells in the PWM are not yet green-fluorescent (Fig. 1p). Consistently, we found that Gad67-GFP/BrdU double-labeled cells cannot be detected earlier than $24 \mathrm{~h}$ after administration of the nucleotide analog (Fig. 1q,r). Therefore, GABAergic interneuron progenitors preferentially proliferate in the PWM and upregulate Pax-2 only at the time of their last division. Young postmitotic interneurons sojourn for a rather long period in the PWM, where they initiate their GABAergic differentiation.

\section{All types of cerebellar GABAergic interneurons are generated according to a common ontogenetic sequence}

The different categories of cerebellar GABAergic interneurons are generated during largely overlapping time windows between E13 and P15, starting with cells destined for deep nuclei and progressing to those eventually located in the granular and molecular layers of the cortex (Miale and Sidman, 1961; Rakic, 1973; Altman and Bayer, 1997). This pattern of generation may result from parallel neurogenic processes, in which different categories of interneurons are produced by distinct progenitors through independent mechanisms. Alternatively, all cerebellar interneurons could derive from a common precursor pool, from which newborn cells are progressively assigned to specific laminar positions and mature identities.

To clarify this point, we pulsed BrdU to wild-type rats, Pax-2GFP mice, and Gad67-GFP mice throughout the period of interneuron genesis (E15, P1, P7 rats, Fig. $2 a-c$,e; E12, P0, P5, P10 mice, supplemental Fig. 2, available at www.jneurosci.org as supplemental material), and determined the position and phenotype of BrdU-retaining interneurons at P30. As shown in Figure 2e, cells labeled with BrdU at different ages eventually came to reside in distinct cortical positions, such that the earliest-born cells were preferentially located deeper, whereas later-born elements occupied progressively more superficial placements $(p<0.0001$; oneway ANOVA for age at labeling vs position at P30). The relationship linking birth date and laminar fate was further corroborated by the observation that, after a single BrdU pulse, heavily stained cells, which stopped dividing just after labeling, were located in deeper positions than lightly labeled cells, whose BrdU content had been diluted because of continued proliferation (Fig. $2 d$, supplemental Fig. 3, available at www.jneurosci.org as supplemental material). Cohorts of cells that shared the same birth date were consistently located in restricted laminar positions, regardless of whether they were of the same phenotype or belonged to distinct classes (e.g., the Golgi, Lugaro and basket neurons labeled by BrdU injections at P1). The continuous inside-out progression of interneuron genesis, together with the observation that cells of different categories that share the same laminar fate are born at the same time, are consistent with the view that the different classes of interneurons originate by a common developmental process.

\section{Transplanted GABAergic interneurons differentiate according to local ontogenetic schedules}

BrdU labeling experiments show that laminar position and phenotype of cerebellar GABAergic interneurons are related to cell birth date. However, it is unclear whether these two features are definitively established at the time of the last mitosis, and whether they are determined by a common mechanism or separate mechanisms. To address these points we used heterochronic transplantation to assess how laminar fate and neurochemical phenotype of donor cells are influenced by their previous history or by the recipient environment.

We first transplanted cell suspensions obtained from E14, P1, or P7 $\beta$-actin-GFP rats to E15, P1, or P7 wild-type recipients (Fig. $2 f$ ). In line with our previous findings (Leto et al., 2006), heterochronically transplanted cells always acquired mature phenotypes typical of the recipient's age (Fig. $2 j-l$ ). The GFP-tagged donor cells always displayed type-specific morphological and neurochemical traits (Fig. $2 j-l$; supplemental Fig. $1 k-o$, available at www.jneurosci.org as supplemental material) that were consistent with their placement in the recipient cortex. For instance, out of a sample of 988 parvalbumin-immunopositive neurons (from 5 transplants), only 8 were not located in the molecular layer. Similarly, calretinin-positive cells were exclusively found in the granular layer $(n=22$; supplemental Fig. $1 m$, available at www.jneurosci.org as supplemental material) or in the deep nuclei $(n=10$; supplemental Fig. $1 l$, available at www.jneurosci.org as supplemental material), and NeuN-positive cells were all in the deep nuclei ( $n=14$; supplemental Fig. $1 k$, available at www. jneurosci.org as supplemental material).

Regardless of donor age, the precise positions occupied by grafted cells were strictly dependent on the host developmental stage. In progressively older cerebella, the final placement of donor interneurons shifted according to a clear inside-out positional gradient (Fig. $2 g-i$ ). Most strikingly, the laminar fate of the grafted cells was identical to that of the host interneurons born on the day of transplantation (compare Fig. $2 g-i$ to Fig. $2 e$; one-way ANOVA with Bonferroni's multiple comparisons, all $p>0.05$ : no significant differences were found between the positions eventually taken by endogenous cells born at E14, P1, and P7 and cells transplanted to recipients of these ages). Therefore, regardless of their age, donor interneurons promptly adapt to heterochronic conditions and acquire identities and laminar positions dictated by the host ontogenetic stage.

These results suggest that donor cells acquire host-specific positions and phenotypes because they entrain into local ontogenetic processes and develop according to the same mechanisms as endogenous interneurons. Alternatively, grafted cells may colonize the recipient cerebellum following noncanonical routes (Carletti et al., 2008; Williams et al., 2008), and adopt mature phenotypes under the influence of local cues provided by the microenvironment at their final destination. Hence, we examined short-term transplants to elucidate the modes of proliferation, engraftment, and differentiation of donor interneurons.

To establish where donor interneuron progenitors proliferate, we transplanted P7 cells from $\beta$-actin-GFP rats or mice to P1 syngenic hosts. Pax-2-GFP or Gad67-GFP mice could not be used for these experiments because, as shown above, these reporters are not expressed by actively proliferating interneuron progenitors. Recipient animals, which were killed 1, 2, or 4 d posttransplantation, received a BrdU injection $6 \mathrm{~h}$ before perfusion to label dividing cells. Excluding grafted granule cell progenitors in the external granular layer (Williams et al., 2008), virtually all BrdU-labeled GFP-positive cells were located in the PWM (Fig. $3 a, b)$. Although we could not distinguish cell types within this mixed population of dividing elements, it is clear that if donor interneuron progenitors proliferate in the recipient cerebellum (see below), they preferentially do so in the PWM, just like endogenous interneuron precursors (Fig. $1 a-c$ ).

To investigate the engraftment, migration, and differentiation 

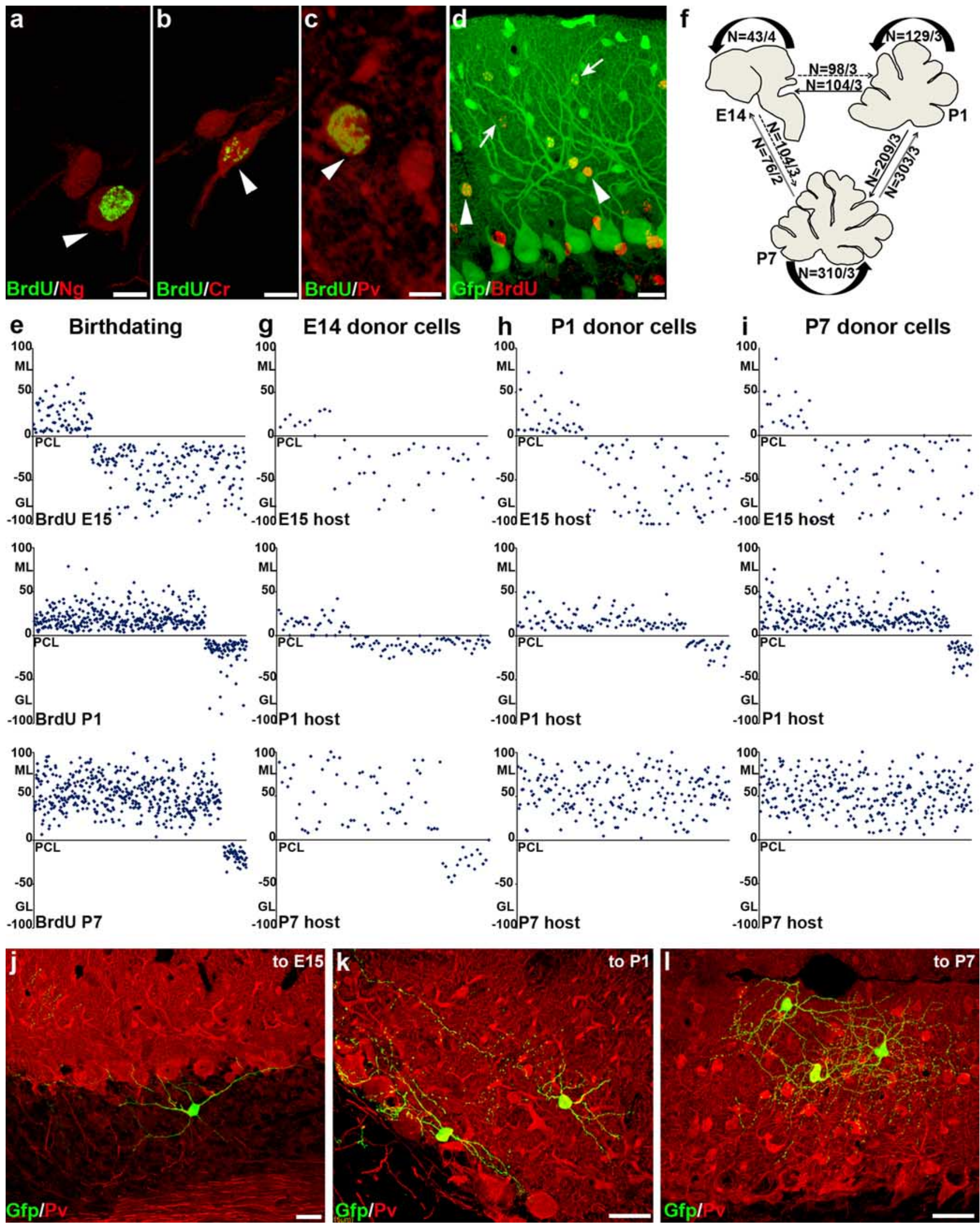

Figure 2. Birth-dating and laminar distribution of endogenous and transplanted GABAergic interneurons. $\boldsymbol{a}-\boldsymbol{c}$, BrdU-positive cells labeled with type-specific markers used to identify mature cerebellar GABAergic interneurons (pictures taken from wild-type rat cerebella): neurogranin (NG) (red in $\boldsymbol{a}$ ) and calretinin (CR) (red in $\boldsymbol{b}$ ) for Golgi and Lugaro cells of the granular layer (GL), parvalbumin (PV) (red in c) for basket and stellate cells in the molecular layer (ML). $\boldsymbol{d}$ shows the different laminar positions of strong (arrowheads) and faint (arrows) BrdU-immunoreactive interneurons in the ML of a P30 Gad67-GFP mouse (BrdU was injected at P5). The graphs in e show the laminar position of rat interneurons that incorporated BrdU injected at E15, P1, and P7 (two pulses within $8 \mathrm{~h}$ for each time point; $n=2-4$ cases/time points; all animals were killed at P30). Note the inside-out positional gradient of interneuron generation (one-way ANOVA with Bonferroni's multiple comparisons test on the position of interneurons born at the three examined ages: $p<0.0001$ ). To analyze the laminar fate of transplanted (Figure legend continues.) 
of transplanted GABAergic interneurons in relation to other donor cells, we performed additional transplants using $\beta$-actinRFP/Pax-2-GFP double transgenic mice, in which all cells are red fluorescent (Fig. 3i) and GABAergic interneurons are also green fluorescent (Fig. 3j). Shortly after transplantation, the vast majority of transplanted cells were located in the PWM, from where they gradually spread to the cortex (Fig. $3 c-e, i, j$ ). Young postmitotic interneurons, highlighted by increasing expression of the GFP reporter, initially appeared in the PWM (Fig. $3 c-e$ ) and later emigrated to the overlying cortex (Fig. $3 e-h$ ), where they acquired mature phenotypes following typical morphogenic phases (Fig. 3g-h) (Altman and Bayer, 1997; Simat et al., 2007a). Therefore, donor interneurons do not engraft in ectopic positions or follow unusual migratory pathways to reach their final destination, but faithfully replicate transit through the PWM and cortical dispersal of their endogenous counterparts.

\section{The position and phenotype of GABAergic cerebellar interneurons are not specified during their last mitosis}

To assess whether the mature phenotypes and laminar positions of cerebellar interneurons are specified at the time of their birth, we next asked whether the fate of late (P7) interneuron progenitors heterochronically transplanted to a more juvenile environment (E15 or P1) was dependent on the time and place of their final cell division.

We first grafted P7 $\beta$-actin-GFP cells to E15, P1, or P7 rats, pulsed BrdU to the host animals during the first day after transplantation, and examined the recipient cerebella at P30. In all conditions, the donor cells, normally destined to generate exclusively molecular layer interneurons (Fig. 2e), acquired positions and phenotypes consistent with the host ontogenetic stage. A fraction of these cells (Fig. $4 a-c$, g-i; 10/47 in E15, 87/579 in P1, and 197/1173 in P7 recipients) was labeled by anti-BrdU antibodies, showing that they underwent one or more rounds of cell division after transplantation.

To probe whether proliferation within the recipient environment is critical to the entrainment of transplanted cells to hostspecific fates, we prepared P7-P1 transplants from donors pulsed with $\operatorname{BrdU} 8$ or $24 \mathrm{~h}$ before cell dissection (Fig. $4 d, e$ ). In the former condition, BrdU-labeled cells carried out the last $\mathrm{S}$ phase in the donor cerebellum, whereas in the latter, they likely completed the whole cell division before dissection and transplantation. We then analyzed the fate of label-retaining, strongly BrdUlabeled, transplanted cells, to exclude donors that underwent additional rounds of cell division in the recipient tissue (Fig. $4 j-m)$. Again, the results were clear-cut: label-retaining interneu-

\section{$\leftarrow$}

(Figure legend continued.) interneurons, we performed the experiments sketched in $\boldsymbol{f}$; cerebellar cells from E14, P1, and P7 rat $\beta$-actin-GFP donors were grafted to either age-matched or heterochronic wild-type rat recipients, which were killed 1 month post-transplantation. For each condition, represented by an arrow linking donor to host, the total number of transplanted interneurons considered and the number of examined cases are indicated. $\boldsymbol{g}-\boldsymbol{i}$, Scatter graphs illustrating the distribution of transplanted interneurons in the recipient cortex. Regardless of the donor age, the position of transplanted interneurons is always strictly dependent on the host age. In addition, the laminar fate of donor cells corresponds to that of host interneurons born on the day of transplantation (compare $\boldsymbol{g}-\boldsymbol{i}$ with $\boldsymbol{e}$; one-way ANOVA with Bonferroni's multiple comparisons on the layering positions of cells grafted in E15, P1, and P7 hosts and those of local GABAergic interneurons born on the same day: $p>0.05)$. $\boldsymbol{j}-\mathbf{l}$, Interneurons generated by P7 rat $\beta$-actin-GFP donors in E15 (j), P1 ( $(\boldsymbol{k})$, and P7 (I) wild-type rat recipients: note the host-specific position and phenotypes acquired by transplanted cells 1 month after transplantation in cerebella of different ages. PCL, Purkinje cell layer. Scale bars: $(\boldsymbol{a}, \boldsymbol{b}, \boldsymbol{c}), 10$ $\mu \mathrm{m} ;(j-I), 50 \mu \mathrm{m}$. rons occupied positions and acquired mature phenotypes typical of the recipient age (Fig. $4 d$, $e$; one-way ANOVA with Bonferroni's multiple comparison test among BrdU-positive and BrdUnegative transplanted interneurons and endogenous interneurons born at $\mathrm{P} 1$ does not reveal significant differences, $p=0.43$ ). This indicates that even cells that completed their last mitosis in the donor cerebellum are capable to acquire host-specific identities and laminar fates. To independently test this conclusion, we transplanted fluorescence-activated cell sorting (FACS)-purified Gad67-GFP-positive cells. As documented above (Fig. 1q,r), these cells are postmitotic, since GFP expression only starts $24 \mathrm{~h}$ after the terminal division. Again, P7 Gad67-GFP interneurons transplanted to P1 cerebella acquired host-specific laminar fates and phenotypes (Fig. $4 f, n, o$ ). Therefore, the mature phenotype and final position of cerebellar interneurons are temporally related to their birth date, but they are not determined during the last mitosis.

\section{Specification of transplanted interneurons depends on the instructive potential of the PWM microenvironment}

The observation that young postmitotic interneurons remain in the PWM for a protracted time suggests that their position and phenotype are determined during this period. Transplanted interneurons, too, engraft in the PWM and share the same fate as local interneurons born on the same day, implying that they become specified soon after transplantation. This indicates that dissociation disrupts some crucial interactions in the donor PWM that regulate the proliferation and differentiation of cerebellar interneurons. As a consequence, individual donor cells are directly exposed to the recipient PWM environment that rapidly induces their maturation.

To test this hypothesis, and to see whether the PWM milieu provides instructive information for newly born interneurons, we compared the fate of P7 donor cells grafted to P1 cerebella as single-cell suspensions, or as pellets of dissociated and reaggregated cells, or as solid pieces of PWM. The three transplantation paradigms yielded similar results (Fig. $5 a-f$; one-way ANOVA with Bonferroni's multiple comparison test, $p=0.29$ ). Donor interneurons acquired fully mature traits and proper anatomical integration in the recipient tissue, and their position and phenotypes were consistent with those of host interneurons (Fig. 2e; one-way ANOVA for final laminar position, $p=0.26$ ). Therefore, $\mathrm{P} 7$ cells that have not been dissociated, or that that have been dissociated and reaggregated, are still able to fully adapt to the recipient environment.

This result suggests that the donor PWM microenvironment maintained in solid grafts does not provide adequate conditions to determine the fate of the grafted interneurons. However, it may be possible that the highly neurogenic milieu of the P1 host cerebellum exerts an overwhelming influence that masks the intrinsic properties of the donor tissue. To elucidate this point we compared the fate of P1 and P7 donor cells transplanted as suspensions or solid PWM blocs into P30 cerebella, in which interneuron genesis has ceased. Cell suspensions from both donors exclusively yielded stellate cells, positioned in the most superficial aspect of the molecular layer (Fig. $5 g-i$ ). On the contrary, solid transplants of either age produced high numbers of interneurons, distributed throughout the host white matter and cortical layers (Fig. $5 i-n$ ). The transplanted interneurons acquired clear-cut distinctive morphological and neurochemical features that allowed identification of their phenotype, even though the majority of them occupied obvious ectopic positions (Fig. 5i,j). Most interestingly, although the spatial distribution of grafted cells in 

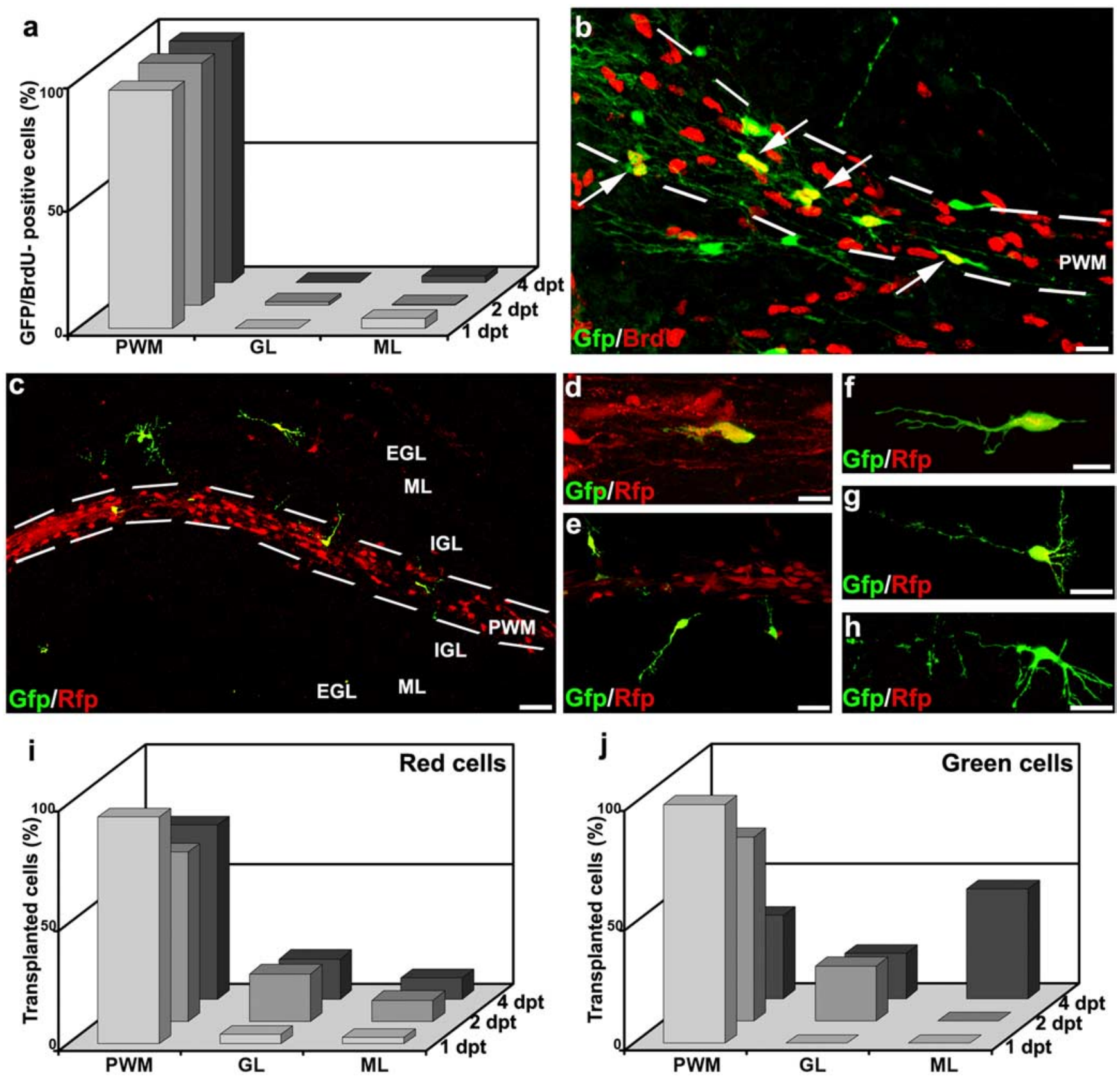

Figure 3. Differentiation of transplanted interneuron progenitors. $\mathbf{a}$, $\mathbf{b}$ document the distribution of BrdU-immunoreactive cells dissected from P7 $\beta$-actin-GFP donor rats, 1, 2, or $4 \mathrm{~d}$ after transplantation to P1 syngenic hosts (11-106 cells/case, 3 cases/time point). BrdU was injected $6 \mathrm{~h}$ before killing. The vast majority of donor cells proliferate in the PWM (arrows in $\boldsymbol{b}$ ). c $-\boldsymbol{j}$ shows the progressive integration of P7 cerebellar progenitors derived from Pax-2GFP/ $\beta$-actin RFP mice transplanted to P1 mouse cerebella killed $4 \mathrm{~d}$ after graft. Young postmitotic interneurons, highlighted by increasing expression of the GFP reporter, initially appear in the PWM $(\boldsymbol{c}, \boldsymbol{d})$ and move to the cortex $(\boldsymbol{e})$, where they progressively acquire mature phenotypic traits. $\boldsymbol{f}$ - $\boldsymbol{h}$, Typical morphogenic phases of molecular layer (ML) interneurons, which first migrate to the edge of the external granular layer $(\boldsymbol{f})$ and then develop characteristic neurites $(\boldsymbol{g}, \boldsymbol{h}) . \boldsymbol{i}, \boldsymbol{j i l l u s t r a t e ~ t h e ~ d i s t r i b u t i o n ~ o f ~ t h e ~ w h o l e ~}$ population of RFP-positive grafted cells (i) or of the Pax-2/GFP interneurons ( $(j)$ at 1, 2, and $4 \mathrm{~d}$ after transplantation: note the progressive shift of donor interneurons from the PWM to the cortex. Survival times: $\boldsymbol{b}, 1$ day post-transplantation (dpt); $\boldsymbol{C}-\boldsymbol{h}, 4 \mathrm{dpt}$. GL, Granular layer. Scale bars: $(\boldsymbol{b}, \boldsymbol{g}, \boldsymbol{h}), 20 \mu \mathrm{m} ;(\boldsymbol{c}, \boldsymbol{e}), 50 \mu \mathrm{m} ;(\boldsymbol{d}, \boldsymbol{f}), 10 \mu \mathrm{m} ;(\boldsymbol{e}-\boldsymbol{k}, \boldsymbol{o}), 20 \mu \mathrm{m}$.

the host cerebellum was similar for both donors (Fig. $5 i$, unpaired Student's $t$ test, $p=0.7)$, the phenotypic repertoire varied according to the donor age: P7 grafts exclusively yielded parvalbuminimmunopositive basket/stellate cells (Fig. $5 k, n)$, whereas P1 grafts also produced a consistent fraction of Golgi neurons (Fig. $5 k-m)$. Therefore, whereas dissociated cells grafted to P30 cerebella exclusively acquired the phenotypes of the latest generated stellate cells, en bloc PWM grafts yielded numerous interneurons that survive in the host environment even in unusual positions and acquired clear-cut donor-specific phenotypes, disclosing the endogenous neurogenic capabilities of the donor PWM tissue.

\section{Discussion}

To investigate the generation of cerebellar GABAergic interneurons, we combined birth-dating, heterochronic transplantation, and fate analysis. Our results reveal that the variety of cerebellar interneurons is produced through a peculiar postmitotic process, different from the mechanisms underlying interneuron genesis 
in other CNS regions. Further, we identify the PWM as the microenvironment critical to defining the laminar position and mature phenotype of young interneurons, which retain wide developmental potentialities up to late ontogenetic stages. Although the acquisition of positional and neurochemical identities is highly correlated, they may be uncoupled, indicating that they are mechanistically independent.

\section{Positional and neurochemical identities of cerebellar GABAergic interneurons are specified after the last mitosis} Cerebellar GABAergic interneurons derive from Pax-2-positive progenitors (Maricich and Herrup, 1999) that proliferate in the PWM (Zhang and Goldman, 1996). Here, we provide direct evidence that these progenitors upregulate Pax-2 during their last division. Thereafter, the young postmitotic interneurons sojourn in the PWM for a rather long period, although they progressively acquire distinctive GABAergic traits. Cohorts of interneurons that leave the cell cycle at the same time settle into restricted cortical laminae, showing that their final placement is temporally linked to their birth date. The latency between proliferation and final differentiation of cortical interneurons has been previously interpreted as a pausing period required to match the delayed maturation of the cortical cytoarchitecture (Rakic, 1973). Our results indicate that this time span is crucial for cell specification.

The inside-out sequence of interneuron production indicates that phenotypes and positions may be established by a common mechanism related to the cell birth date. In some cases, however, interneurons that are born at the same time and share the same laminar fate belong to different phenotypes, suggesting that specification of these two features could be uncoupled. A possible explanation is that young interneurons are assigned to precise cortical positions at the time of their birth date in the PWM, but become committed to specific phenotypes only when they reach their final placement. For instance, molecular layer interneurons might be targeted to their laminar positions by their sequential generation, so that late-generated neurons migrate to progressively more superficial positions because the deeper ones are already occupied. Then, the acquisition of distinctive traits of basket or stellate cells is determined by molecular cues (Ango et al., 2004) or anatomical constraints (Rakic, 1972; Sultan and Bower, 1998) of the local environment at their homing position. Nevertheless, our solid grafts to adult hosts show that major morphological and neurochemical traits of molecular layer interneurons can be acquired even in strongly unusual positions. Indeed, cerebellar interneurons develop clear-cut distinctive features when they are plated in vitro (Baader et al., 1999; Koscheck et al., 2003), ectopically placed within the cerebellum (Jankovski et al., 1996; this study), or grafted to extracerebellar sites (Jankovski and Sotelo, 1996; Carletti et al., 2002). Together with the finding that transplanted interneurons adopt host-specific identities and placements by entraining into the recipient neurogenic mechanisms, these observations indicate that both position and phenotype are determined while young interneurons are still in the PWM. However, the fact that expression of type-distinctive traits is not dependent on the correct placement suggests that phenotypic maturation and acquisition of laminar fate are regulated by separate mechanisms.

Despite the relationship linking interneuron birth date and fate, transplantation experiments show that postmitotic cells are still able to switch their identities as dictated by the host. As exemplified by upregulation of Pax-2, crucial ontogenetic steps occur at the time of the last mitosis, but these events do not involve terminal commitment to a particular interneuron cate- gory. Rather, it is likely that exit from the cell cycle defines a generic GABAergic interneuron identity, marks the onset of differentiation, and makes the cell competent to choose its specific phenotype in response to extrinsic cues. However, the observation that postmitotic interneurons maintain the expression of mitotic markers, such as Ki67 (Weisheit et al., 2006), suggests that they do not enter a full-blown $\mathrm{G}_{0}$, but persist in an intermediate state required to complete specification (Schilling et al., 2008).

\section{The PWM microenvironment is instructive for naive cerebellar interneurons}

Our observations indicate that newborn neurons in the PWM are exposed to spatiotemporally patterned cues that orientate their choices toward different interneuron categories. Although each class is preferentially generated during a defined developmental period, interneurons with different locations and phenotypes can be born at the same time (Fig. $2 e-i$ ). The long duration and large overlap of the generation periods of the different interneuron categories suggest that the information required to specify each type may change in intensity but persists in the maturing cerebellum. As a consequence, the probability of acquiring a certain identity varies according to the time or place of the interneuron's birth. It might be possible that specification cues act by selecting among distinct subsets of fate-restricted cells, each destined to generate a specific class of interneurons. Evidence for the existence of such subpopulations is lacking (Glassmann et al., 2009). In contrast, different reports point to a common, molecularly defined lineage for all cerebellar interneurons (Maricich and Herrup, 1999; Weisheit et al., 2006; Simat et al., 2007a), and several observations corroborate this view: (1) Pax-2-positive cells derive from a restricted domain in the rostromedial region of the VN (Maricich and Herrup, 1999; Zordan et al., 2008); (2) grafts from this region are enriched in GABAergic interneurons, whereas grafts from other VN domains are depleted (Grimaldi et al., 2009); (3) different types of interneurons are clonally related, implying that they descend from a common ancestor (Mathis et al., 1997; Mathis and Nicolas, 2003). Then, it may be possible that the variety of interneurons originates from a single population of initially multipotent progenitors, whose developmental potential is progressively restricted. However, heterochronic transplantation definitely shows that even cells isolated at the latest developmental stages maintain full potentialities (Leto et al., 2006). Therefore, our results indicate that the phenotype of cerebellar interneurons is established by an instructive mechanism that dictates fate choices taken by multipotent cells residing in the PWM. Thereafter, terminally committed interneurons acquire typespecific features by unfolding a cell-autonomous plan, whereas extrinsic cues modulate their survival (Englund et al., 2006; Zanjani et al., 2006), migration (Guijarro et al., 2006), and neuritogenesis (Mertz et al., 2000; Rico et al., 2002; Ango et al., 2004).

Instructive cues for young interneurons might derive from nearby neuronal populations, as proposed for interneuron specification in the cerebral cortex (Hevner et al., 2004; Hammond et al., 2006). Thus, embryonic deep nuclei projection neurons might induce nearby progenitors to adopt a nuclear interneuron phenotype, whereas precursors in the subcortical PWM could differentiate into granular layer interneurons under the influence of Purkinje cells. After birth, granule cells that populate the nascent internal granular layer might stimulate the production of molecular layer interneurons.

Despite the attractive simplicity of this model, our present observations point to mechanisms within the PWM itself as cru- 

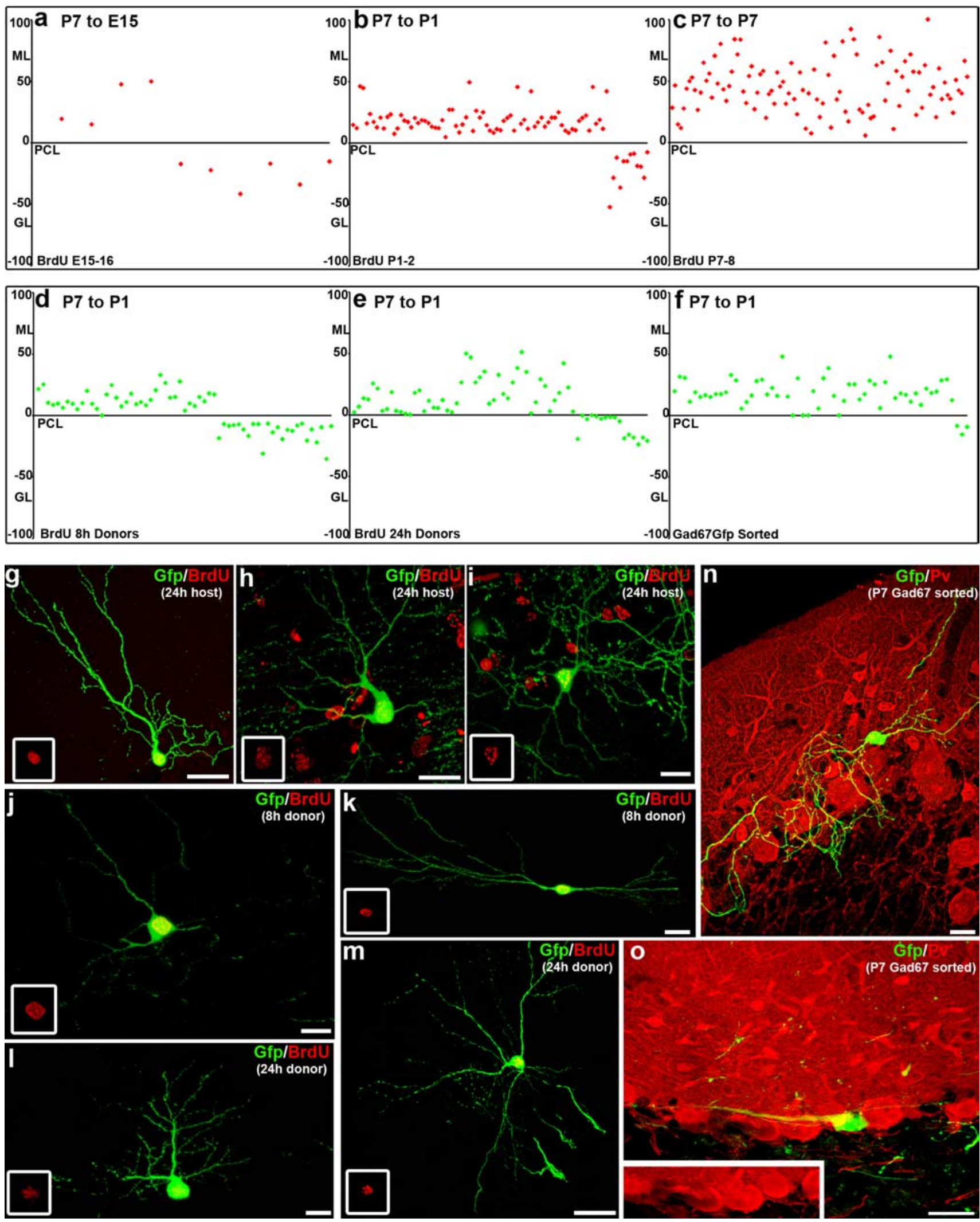

(P7 Gad67 sorted)

Figure 4. Laminar fate of GABAergic interneurons is independent from the environment of the last mitosis. $\boldsymbol{a}$ - $\mathbf{c}$ illustrates the laminar fate acquired by BrdU-positive rat $\beta$-actin-GFP interneurons generated by P7 donors transplanted to E15 (a), P1 (b), and P7 (c) wild-type rat recipients. The nucleotide analog was administered in the first $24 \mathrm{~h}$ after transplantation. $\boldsymbol{d}-\boldsymbol{m}$, The phenotype and distribution of these donor cells (examples are depicted in $\boldsymbol{g}-\boldsymbol{i}$ ) match those of endogenous interneurons born on the day of transplantation (Fig. 2e, one-way ANOVA with Bonferroni's multiple comparisons, $p>0.05)$. P7 rat $\beta$-actin GFP-derived interneurons transplanted to P1 hosts, which captured BrdU administered $8 \mathrm{~h}(\boldsymbol{d}, \boldsymbol{j}, \boldsymbol{k})(61$ cells $/ 8$ cases) or $24 \mathrm{~h}(\boldsymbol{e}, \mathbf{l}, \boldsymbol{m})(64$ cells $/ 6$ cases) before dissection, also reached laminar positions consistent with the host age (one-way ANOVA with Bonferroni's multiple comparisons, $p=0.43$; both conditions were significantly different from the laminar position occupied by interneurons born at P7; Student's $t$ test, $p<0.0001$ ). Similar results were obtained with fluorescence-activated cell-sorted P7 Gad67-GFP postmitotic donor cells, which also acquired host-specific phenotypes [e.g., basket neurons in the molecular layer (ML) (n), and Lugaro cells in the granular layer (GL) (o); (Figure legend continues.) 

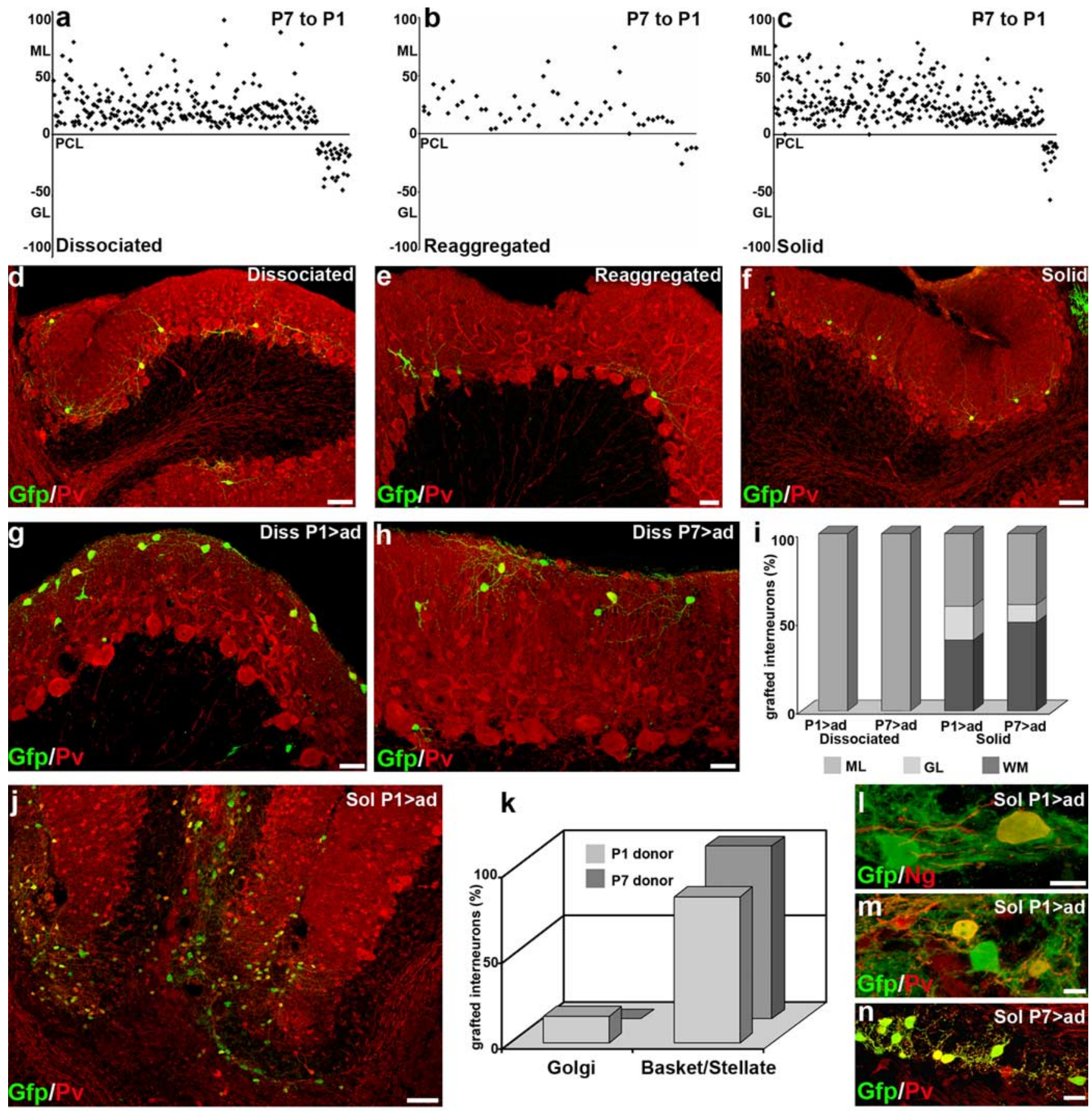

Figure 5. Endogenous neurogenic potential of the PWM microenvironment. $\boldsymbol{a}$ - $c$ illustrates the positions acquired by P7 rat $\beta$-actin-GFP-positive interneurons transplanted to P1 wild-type rat recipients as single-cell suspensions $(\boldsymbol{a})$, as reaggregated cells $(\boldsymbol{b})$, or as solid pieces of PWM (c) analyzed 1 month after graft. The different procedures yielded similar phenotypic repertoires and laminar positions (one-way ANOVA with Bonferroni's multiple comparison test; $p=0.29) . \boldsymbol{d}-\boldsymbol{f}$ shows examples of transplanted GFP-positive interneurons (green) obtained from dissociated ( $\boldsymbol{d}$ ), reaggregated $(\boldsymbol{e})$, or solid $(\boldsymbol{f})$ grafts. $\boldsymbol{g}-\boldsymbol{i}$, Preferential localization of dissociated P1 $(\boldsymbol{g})$ or P7 (h) cells transplanted to adult hosts. Donors of both ages yielded stellate cells located close to the molecular layer (ML) surface $(\boldsymbol{i})$. $\boldsymbol{j}$ - $\boldsymbol{n}$, Solid grafts from P1 or P7 $\beta$-actin-GFP-positive rat donors transplanted to adult cerebella give rise to numerous interneurons distributed throughout the host cortex, and white matter (WM) $(\boldsymbol{i}, \boldsymbol{j})$. Even in ectopic positions, the transplanted cells produced phenotypic repertoires consistent with their donor age $(\boldsymbol{k})$. For instance, P1 cells in the host white matter generated both neurogranin-positive granular layer (GL) interneurons (red in $I$ ) and parvalbumin-positive ML interneurons (PV, red in $\boldsymbol{m}$ ), whereas P7 donors exclusively produced the latter phenotype (n). Sol, Solid graft; Diss, dissociated cell graft; Ad, adult; PCL, Purkinje cell layer. Scale bars: $(\boldsymbol{d}, \boldsymbol{f}, \boldsymbol{J}), 100 \mu \mathrm{m} ;(\boldsymbol{e}, \boldsymbol{g}, \boldsymbol{h}), 50 \mu \mathrm{m} ;(\boldsymbol{n}), 20 \mu \mathrm{m} ;(\boldsymbol{I}, \boldsymbol{m}), 10 \mu \mathrm{m}$.

$\leftarrow$

(Figure legend continued.) the inset shows that this cell is not immunopositive for parvalbumin] and positions ( $\boldsymbol{f}$; Student's $t$ test vs endogenous interneurons born at $\mathrm{PO}, p=0.12$, vs endogenous interneurons born at $P 5, p<0.0001)$. In all instances, the recipient animals were killed 1 month after transplantation. PCL, Purkinje cell layer. Scale bars: $(\boldsymbol{h}-\boldsymbol{I}, \boldsymbol{n}), 20 \mu \mathrm{m} ;(\boldsymbol{g}, \boldsymbol{m}, \boldsymbol{0}), 50$ $\mu \mathrm{m}$. cial regulators of interneuron genesis. The endogenous neurogenic potential of the PWM milieu is disclosed by the solid graft experiments and further supported by the observation that dissociated cells acquire host-specific phenotypes after transit through this germinal territory. The cell composition and molecular microenvironment of the PWM are scarcely defined. In addition to maturing afferent and efferent cortical axons, it contains 
newly born neurons and glia, their progenitors, and, likely, stem cells with broader potentialities (Klein et al., 2005; Lee et al., 2005). Interactions between local PWM elements may be important to regulate the balance between proliferation and differentiation, as demonstrated for the external granular layer (Pons et al., 2001). Furthermore, evidence has been provided that patterned expression of matrix components control the sorting and migration of GABAergic interneurons (Gliem et al., 2006; Baier et al., 2007). Similarly, the increased frequency of Golgi neurons in ErbB4 null mice suggests that ErbB4/neuregulin signaling may participate to specify certain interneuron categories (Tidcombe et al., 2003). Therefore, although the contribution of signals from outside the PWM cannot be excluded, interactions that occur within the rapidly evolving environment of the embryonic and postnatal PWM are likely crucial to determine interneuron specification and coordinate their spatiotemporal pattern of generation.

\section{A peculiar strategy to generate inhibitory interneurons}

Adaptive function of neural networks requires the activity of multiple, task-specific inhibitory components. As a consequence, ontogenetic processes must be able to produce wide interneuron repertoires in appropriate quantities, and according to precise spatiotemporal patterns. Whereas in most CNS regions this goal is reached by recruiting precursors from distinct neurogenic territories, in the cerebellum it is achieved by creating phenotypic diversity from a single source. The reasons for this peculiarity remain uncertain. The exclusive origin of the cerebellum from an early and restricted germinal territory likely requires secondary germinal sites to expand certain neuron populations, and notably glutamatergic and GABAergic interneurons (Carletti and Rossi, 2008). Given the strict relationship linking cerebellar size to its main afferent territories (e.g., cerebral cortex or spinal cord), late specification in the PWM could represent a means to match cell numbers and types to concomitant variations of extracerebellar inputs, thus making the cerebellar network highly adaptable to evolutionary demands.

\section{References}

Altman J, Bayer SA (1997) Development of the cerebellar system in relation to its evolution, structures and functions. Boca Raton, FL: CRC.

Ango F, Di Cristo G, Higashiyama H, Bennett V, Wu P, Huang ZJ (2004) Ankyrin-based subcellular gradient of neurofascin, an immunoglobulin family protein, directs GABAergic innervation at Purkinje axon initial segment. Cell 119:257-272.

Baader SL, Bergmann M, Mertz K, Fox PA, Gerdes J, Oberdick J, Schilling K (1999) The differentiation of cerebellar interneurons is independent of their mitotic history. Neuroscience 90:1243-1254.

Baier C, Baader SL, Jankowski J, Gieselmann V, Schilling K, Rauch U, Kappler J (2007) Hyaluronan is organized into fiber-like structures along migratory pathways in the developing mouse cerebellum. Matrix Biol 26:348-358.

Bastianelli E (2003) Distribution of calcium-binding proteins in the cerebellum. Cerebellum 2:242-262.

Carletti B, Rossi F (2008) Neurogenesis in the cerebellum. Neuroscientist 14:91-100.

Carletti B, Grimaldi P, Magrassi L, Rossi F (2002) Specification of cerebellar progenitors following heterotopic/heterochronic transplantation to the embryonic CNS in vivo and in vitro. J Neurosci 22:7132-7146.

Carletti B, Williams IM, Leto K, Nakajima K, Magrassi L, Rossi F (2008) Time constraints and positional cues in the developing cerebellum regulate Purkinje cell placement in the cortical architecture. Dev Biol 317:147-160.

Celio MR (1990) Calbindin D-28k and parvalbumin in the rat nervous system. Neuroscience 32:375-475.

De Marchis S, Bovetti S, Carletti B, Hsieh Y, Garzotto D, Peretto P, Fasolo A, Puche A, Rossi F (2007) Generation of distinct types of periglomerular olfactory bulb interneurons during development and in adult mice: implication for intrinsic properties of the subventricular zone progenitor population. J Neurosci 27:657-664.

Englund CM, Kowalczyk T, Daza RAM, Dagan A, Lau C, Rose MF, Hevner RF (2006) Unipolar brush cells of the cerebellum are produced in the rhombic lip and migrate through developing white matter. J Neurosci 26:9184-9195.

Fogarty M, Grist M, Gelman D, Marin O, Pachnis V, Kessaris N (2007) Spatial genetic patterning of the embryonic neuroepithelium generates GABAergic interneuron diversity in the adult cortex. J Neurosci 27:107935-107946.

Geurts FJ, De Schutter E, Dieudonné S (2003) Unravelling the cerebellar cortex: cytology and cellular physiology of large-sized interneurons in the granular layer. Cerebellum 2:290-299.

Glassmann A, Topka S, Wang-Eckardt L, Anders S, Weisheit G, Endl E, Zimmer A, Schilling K (2009) Basic molecular fingerprinting of immature molecular cortical inhibitory interneurons and their precursors. Neuroscience 159:69-82.

Gliem M, Weisheit G, Mertz KD, Endl E, Oberdick J, Schilling K (2006) Expression of classical cadherins in the cerebellar anlage: quantitative and functional aspects. Mol Cell Neurosci 33:447-458.

Grimaldi P, Parras C, Guillemot F, Rossi F, Wassef M (2009) Origins and control of the differentiation of inhibitory interneurons and glia in the cerebellum. Dev Biol 328:422-433.

Guijarro P, Simo S, Pascual M, Abasolo I, Del Rio JA, Soriano E (2006) Netrin 1 exerts a chemorepulsive effect on migrating cerebellar interneurons in a Dcc-independent way. Mol Cell Neurosci 33:389-400.

Hammond V, So E, Gunnersen J, Valcanis H, Kalloniatis M, Tan SS (2006) Layer positioning of late-born cortical interneurons is dependent on Reelin but not p35 signaling. J Neurosci 26:1646-1655.

Hevner RF, Daza RA, Englund C, Kohtz J, Fink A (2004) Postnatal shifts of interneuron position in the neocortex of normal and reeler mice: evidence for inward radial migration. Neuroscience 124:605-618.

Hoshino M, Nakamura S, Mori K, Kawauchi T, Terao M, Nishimura YV, Fukuda A, Fuse T, Matsuo N, Sone M, Watanabe M, Bito H, Terashima T, Wright CVE, Kawaguchi Y, Nakao K, Nabeshima YI (2005) Ptf1a, a bHLH transcriptional gene, defines GABAergic neuronal fates in cerebellum. Neuron 47:201-213.

Jankovski A, Sotelo C (1996) Subventricular zone-olfactory bulb migratory pathway in the adult mouse: cellular composition and specificity as determined by heterochronic and heterotopic transplantation. J Comp Neurol 371:376-396.

Jankovski A, Rossi F, Sotelo C (1996) Neuronal precursors in the postnatal mouse cerebellum are fully committed cells: evidence from heterochronic transplantation. Eur J Neurosci 8:2308-2320.

Klein C, Butt SJ, Machold RP, Johnson JE, Fishell G (2005) Cerebellum- and forebrain-derived stem cells possess intrinsic regional character. Development 132:4497-4508.

Koscheck T, Weyer A, Schilling RL, Schilling K (2003) Morphological development and neurochemical differentiation of cerebellar inhibitory interneurons in microexplant cultures. Neuroscience 116:973-984.

Lainé J, Axelrad H (1994) The candelabrum cell: a new interneuron in the cerebellar cortex. J Comp Neurol 338:159-173.

Lainé J, Axelrad H (2002) Extending the cerebellar Lugaro cell class. Neuroscience 115:363-374.

Lee A, Kessler JD, Read TA, Kaiser C, Corbeil D, Huttner WB, Johnson JE, Wechsler-Reya RJ (2005) Isolation of neural stem cells from the postnatal cerebellum. Nat Neurosci 6:723-729.

Lee KJ, Jessell TM (1999) The specification of dorsal cell fates in the vertebrate central nervous system. Annu Rev Neurosci 22:261-294.

Leto K, Carletti B, Williams IM, Magrassi L, Rossi F (2006) Different types of cerebellar GABAergic interneurons originate from a common pool of multipotent progenitor cells. J Neurosci 26:11682-11694.

Leto K, Bartolini A, Rossi F (2008) Development of cerebellar GABAergic interneurons: origin and shaping of the "minibrain" local connections. Cerebellum 7:523-529.

Lledo PM, Merkle FT, Alvarez-Buylla A (2008) Origin and function of olfactory bulb interneuron diversity. Trends Neurosci 31:392-400.

Long JZ, Lackan CS, Hadjantonakis AK (2005) Genetic and spectrally distinct in vivo imaging: embryonic stem cells and mice with widespread expression of a monomeric red fluorescent protein. BMC Biotechnol $5: 20$. 
Maricich SM, Herrup K (1999) Pax-2 expression defines a subset of GABAergic interneurons and their precursors in the developing murine cerebellum. J Neurobiol 41:281-294.

Mathis L, Nicolas J (2003) Progressive restriction of cell fates in relation to neuroepithelial cell mingling in the mouse cerebellum. Dev Biol 258:20-31.

Mathis L, Bonnerot C, Puelles L, Nicolas JF (1997) Retrospective clonal analysis of the cerebellum using genetic laacZ/lacZ mouse mosaics. Development 124:4089-4104.

McConnell SK, Kaznowski CE (1991) Cell cycle dependence of laminar determination in developing neocortex. Science 254:282-285.

Mertz K, Koscheck T, Schilling K (2000) Brain-derived neurotrophic factor modulates dendritic morphology of cerebellar basket and stellate cells: an in vitro study. Neuroscience 97303-310.

Miale IL, Sidman RL (1961) An autoradiographic analysis of histogenesis in mouse cerebellum. Exp Neurol 4:277-296.

Milosevich A, Goldman JE (2002) Progenitors in the postnatal cerebellar white matter are antigenically heterogeneous. J Comp Neurol 452:192-203.

Milosevich A, Goldman JE (2004) Potential of progenitors from postnatal cerebellar neuroepithelium and white matter: lineage specified vs. multipotent fate. Mol Cell Neurosci 26:342-353.

Okabe M, Ikawa M, Kominami K, Nakanishi T, Nishimune Y (1997) 'Green mice' as a source of ubiquitous green cells. FEBS Lett 407:313-319.

Pfeffer PL, Payer B, Reim G, di Magliano MP, Busslinger M (2002) The activation and maintenance of Pax2 expression at the mid-hindbrain boundary is controlled by separate enhancers. Development 129:307-318.

Pons S, Trejo JL, Martinez-Morales JR, Marti E (2001) Vitronectin regulates Sonic hedgehog activity during cerebellum development through CREB phosphorylation. Development 128:1481-1492.

Rakic P (1972) Extrinsic cytological determinants of basket and stellate cell dendritic pattern in the cerebellar molecular layer. J Comp Neurol 146:335-354.

Rakic P (1973) Kinetics of proliferation and latency between final cell division and onset of differentiation of cerebellar stellate and basket neurons. J Comp Neurol 147:523-546.

Rico B, Xu B, Reichardt LF (2002) TrkB receptor signaling is required for establishment of GABAergic synapses in the cerebellum. Nat Neurosci 5:225-233.

Rossi F, Borsello T, Strata P (1992) Embryonic Purkinje cells grafted on the surface of the cerebellar cortex integrate in the adult unlesioned cerebellum. Eur J Neurosci 4:589-593.

Schilling K, Oberdick J, Rossi F, Baader SL (2008) Besides Purkinje cells and granule neurons: an appraisal of the cell biology of the interneurons of the cerebellar cortex. Histochem Cell Biol 130:601-615.

Simat M, Ambrosetti L, Lardi-Studler B, Fritschy JM (2007a) GABAergic synaptogenesis marks the onset of differentiation of basket and stellate cells in mouse cerebellum. Eur J Neurosci 26:2239-2256.

Simat M, Parpan F, Fritschy JM (2007b) Heterogeneity of glycinergic and gabaergic interneurons in the granule cell layer of mouse cerebellum. J Comp Neurol 500:71-83.

Sultan F, Bower JM (1998) Quantitative Golgi study of the rat cerebellar molecular layer interneurons using principal component analysis. J Comp Neurol 393:353-373.

Tamamaki N, Yanagawa Y, Tomioka R, Miyazaki J, Obata K, Kaneko T (2003) Green fluorescent protein expression and colocalization with calretinin, parvalbumin, and somatostatin in the GAD67- GFP knock-in mice. J Comp Neurol 467:60-79.

Tidcombe H, Jackson-Fisher A, Mathers K, Stern DF, Gassmann M, Golden JP (2003) Neural and mammary gland defects in ErbB4 knockout mice genetically rescued from embryonic lethality. Proc Natl Acad Sci U S A 100:8281-8286.

Valcanis H, Tan SS (2003) Layer specification of transplanted interneurons in developing mouse neocortex. J Neurosci 23:5113-5122.

Weisheit G, Gliem M, Endl E, Pfeffer PL, Busslinger M, Schilling K (2006) Postnatal development of the murine cerebellar cortex: formation and early dispersal of basket, stellate and Golgi neurons. Eur J Neurosci 24:466-478.

Williams IM, Carletti B, Leto K, Magrassi L, Rossi F (2008) Cerebellar granule cells transplanted in vivo can follow physiological and unusual migratory routes to integrate into the recipient cortex. Neurobiol Dis 30:139-149.

Wonders CP, Anderson SA (2006) The origin and specification of cortical interneurons. Nat Rev Neurosci 7:687-696.

Yamanaka H, Yanagawa Y, Obata K (2004) Development of stellate and basket cells and their apoptosis in mouse cerebellar cortex. Neurosci Res 50:13-22.

Zanjani SH, Selimi F, Vogel MW, Haeberlé AM, Boeuf J, Mariani J, Bailly YJ (2006) Survival of interneurons and parallel fiber synapses in a cerebellar cortex deprived of Purkinje cells: studies in the double mutant mouse Grid2Lc/+ Bax (-/-). J Comp Neurol 497:622-635.

Zhang L, Goldman JE (1996) Generation of cerebellar interneurons from dividing progenitors in white matter. Neuron 16:47-54.

Zordan P, Croci L, Hawkes R, Consalez GG (2008) Comparative analysis of proneural gene expression in the embryonic cerebellum. Dev Dyn 237: $726-1735$. 